\title{
Horizontal Stratification during Deep Convection in the Labrador Sea
}

\author{
ELEANOR FRAJKA-WILLIAMS \\ University of Southampton, Southampton, Southampton, United Kingdom \\ Peter B. Rhines AND Charles C. ERIKSEN \\ University of Washington, Seattle, Washington
}

(Manuscript received 28 March 2013, in final form 23 September 2013)

\begin{abstract}
Deep convection - the process by which surface waters are mixed down to $1000 \mathrm{~m}$ or deeper-forms the primary downwelling of the meridional overturning circulation in the Northern Hemisphere. High-resolution hydrographic measurements from Seagliders indicate that during deep convection-though water is well mixed vertically - there is substantial horizontal variation in density over short distances (tens of kilometers). This horizontal density variability present in winter (January-February) contains sufficient buoyancy to restratify the convecting region to observed levels 2.5 months later, as estimated from Argo floating platforms. These results highlight the importance of small-scale heterogeneities in the ocean that are typically poorly represented in climate models, potentially contributing to the difficulty climate models have in representing deep convection.
\end{abstract}

\section{Introduction}

Deep convection occurs when intense wintertime heat fluxes cool weakly stratified surface waters, resulting in well-mixed surface layers hundreds of meters thick. In the Labrador Sea, the major region for open ocean deep convection in the Northern Hemisphere, cyclonic circulation reduces the surface stratification, while cold, dry winds from over Canada and Siberia cool the ocean (Lazier et al. 2002). This cooling increases the density of the surface water, allowing it to sink in plumes with narrow horizontal scales $(100 \mathrm{~m})$ and fast vertical speeds (up to $10 \mathrm{~cm} \mathrm{~s}^{-1}$ ), mixing waters down to $1000 \mathrm{~m}$ or more (Lilly et al. 1999; Steffen and D'Asaro 2002). During periods of deep convection, density differences between the surface and the base of the mixed layer are small by definition (less than $0.01 \mathrm{~kg} \mathrm{~m}^{-3}$ ) (Lazier et al. 2002). When surface buoyancy losses no longer exceed the lateral input of buoyant waters from surrounding regions, the area again becomes stratified with light waters

Corresponding author address: Eleanor Frajka-Williams, National Oceanography Centre, University of Southampton Waterfront Campus, European Way, Southampton, Hampshire SO14 3ZH, United Kingdom.

E-mail: e.frajka-williams@soton.ac.uk overlying denser waters, via some process of restratification (Marshall and Schott 1999).

While observations have established that convection has a finescale texture and restratifies rapidly to a state with strong "spice" (where temperature and salinity, $T$ and $S$, variability are nearly compensating in density), (Lilly et al. 1999), restratification time scales in models are longer (e.g., Jones and Marshall 1997; Katsman et al. 2004). These numerical studies used a simplified initial density state, either a preconvection state with horizontal isopycnals (Visbeck et al. 1996), or a central wellmixed (horizontally and vertically) column of convected water in a so-called "cylinder collapse" experiment (Jones and Marshall 1997). While the numerical modeling study of Legg and McWilliams (2000) allowed for heterogeneous properties, they found that $T$ and $S$ were largely compensating in density.

The longer, annual time scales of restratification require lateral inputs of buoyant water from the boundary currents to maintain observed heat and salt budgets in the Labrador Sea (Straneo 2006; Schmidt and Send 2007). Recirculating boundary currents have been observed using floats (Lavender et al. 2005), while eddy fluxes have been the focus of several more recent papers. The flux of buoyant waters has been divided into fluxes by three classes of eddies in recent numerical modeling 
studies (Chanut et al. 2008; Gelderloos et al. 2011). The three types are the Irminger rings formed by instability at Cape Desolation, boundary current eddies spawned by instabilities of the boundary current, and convective eddies generated by baroclinic instability of the steep isopycnal slopes formed during deep convection. While the results suggested that different eddy processes were dominant in the two model studies, both focus on the necessity of bringing buoyancy to the convective region to increase stratification before the following year's deep convection. They are not, however, the same processes that control the immediate restratification after deep convection.

For immediate restratification, lateral gradients in mixed layer density are susceptible to baroclinic instability. These instabilities grow eddies which can restratify the mixed layer over a single day (Boccaletti et al. 2007). Observations have demonstrated horizontal gradients in mixed layer density (Cole et al. 2010; Timmermans et al. 2012), while numerical modeling in the North Atlantic showed that such instabilities speed up restratification relative to that by surface warming alone (Mahadevan et al. 2012).

In this study, we present hydrographic observations of deep convection ( $>1000$-m-deep mixed layers) from autonomous underwater gliders. We find that the convective region consists of patches of vertically wellmixed water within a several hundred kilometer-wide region, with temperatures and salinities that vary in the horizontal direction. We find that while $T$ and $S$ are compensating to a degree, there are considerable horizontal gradients in density. This paper will demonstrate that horizontal density variations during the convection period are sufficient to account for postconvection vertical stratification.

\section{Data}

Data used here are from two sources: Seaglider autonomous underwater vehicles and Argo profiling floats. Seagliders profile in a sawtooth pattern from the surface to $1000-\mathrm{m}$ depth with an approximate 1:3 vertical to horizontal slope. Each dive "cycle" consists of a down profile and up profile that takes roughly $9 \mathrm{~h}$ to complete, over a horizontal distance of $6 \mathrm{~km}$. During a single cycle, temperature, conductivity, and pressure are measured at intervals of $0.3-2.4 \mathrm{~m}$. The gliders used here (designated sg014 and sg015) were deployed in the Davis Strait in September 2004, crossed Arctic water masses and traveled south to the region of deep convection in January 2005 (Fig. 1). The sg014 and sg015 collected 41 and 59 profiles, respectively, of fully convecting water (mixed layer depths exceeding $700 \mathrm{~m}$, Fig. 2c) and vertical velocities up to $10 \mathrm{~cm} \mathrm{~s}^{-1}$ (Frajka-Williams et al. 2011).

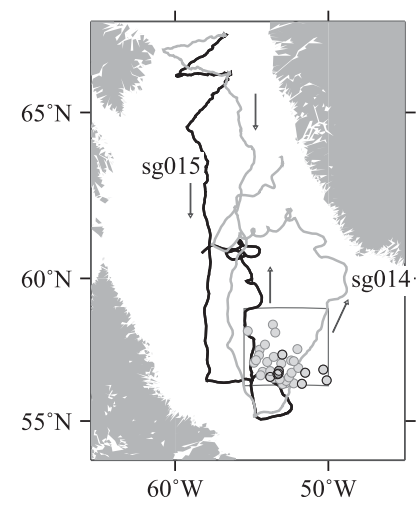

FIG. 1. A map of the Labrador Sea showing the glider and Argo profile locations. The Seaglider tracks are given by the lines (black is $\mathrm{sg} 015$ and gray is $\mathrm{sg} 014$ ). The 36 Argo float profiles were found in the box defined by $56.3^{\circ}-59^{\circ} \mathrm{N}, 50^{\circ}-55.5^{\circ} \mathrm{W}$ and the time period 1 Jan-1 May 2005. Argo profiles locations are given by circles, where the gray circles are for the full period, and the black circles are the nine profiles from Argo where the measured depth of the well-mixed surface layer exceeded $700 \mathrm{~m}$. These nine profiles were all during the period from 25 Jan to 15 Mar.

Hydrographic data from Seagliders were first binned into 2-dbar intervals, and then linearly interpolated across bins where there were no data (at depth) onto an evenly spaced 2-dbar grid. Argo float profiles were coarser than 2 dbar throughout, and so were linearly interpolated onto a regularly spaced 2-dbar grid.

Because of the slow speeds of Seaglider (about $20 \mathrm{~cm} \mathrm{~s}^{-1}$ through water), temporal variations may be aliased into horizontal variability. Seagliders were only in the convection region for a few weeks before they returned north for intended recovery offshore of Nuuk, Greenland. To separate some of the space-time variability, we also analyzed the evolution of temperature and salinity in the convection region from Argo float profiles. An individual Argo float profiles from $2000 \mathrm{~m}$ to the surface every 10 days. The vertical resolution of the floats used here was about 70 samples per $2000 \mathrm{~m}$ and in the convecting region (here, we use $56.3^{\circ}-59^{\circ} \mathrm{N}$ and $50^{\circ}-55.5^{\circ} \mathrm{W}$ ). The 36 quality-controlled profiles were available in this box from 1 January to 1 June 2005 (Fig. 1), with nine profiles showing a well-mixed surface layer deeper than $700 \mathrm{~m}$.

Heat fluxes are from an assimilating model product, the National Centers for Environmental Prediction (NCEP)-National Center for Atmospheric Research (NCAR) Reanalysis II six-hourly product, which show reasonable variability for the region, though biased because of the small number of observations available to correct the model (Renfrew et al. 2002).

We use two measures to describe stratification. The first is a more qualitative indicator: the standard deviation of density in a single profile. For Fig 3, the density 

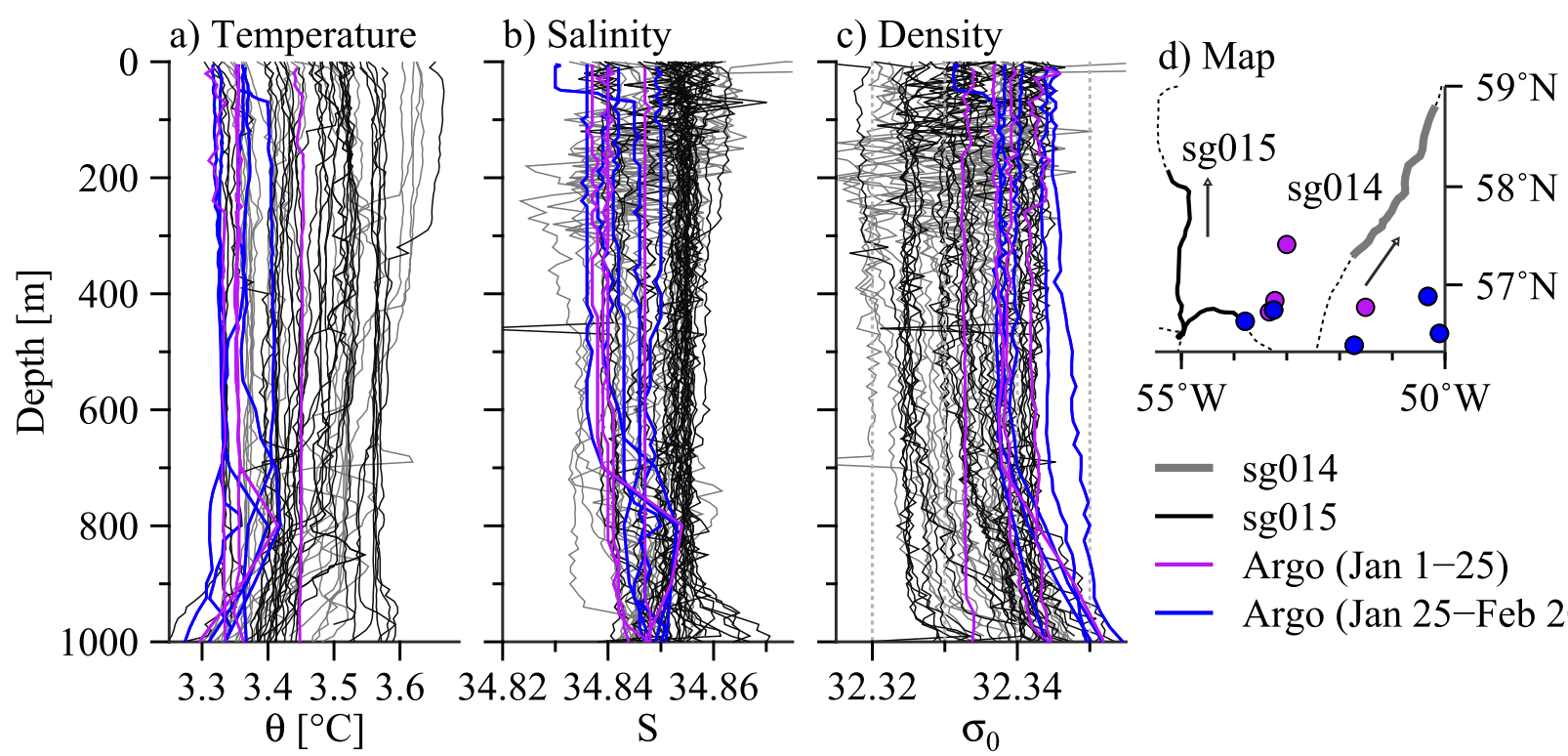

FIG. 2. (a) Potential temperature $\theta$, (b) salinity, and (c) potential density $\sigma_{1}\left(\mathrm{~kg} \mathrm{~m}^{-3}\right)$ of (d) 100 profiles during deepest mixed layers observed by sg015 (black), at the locations specified on Seaglider tracks in the inset map. Profiles in black are from sg015 and gray from sg014. A total of nine Argo float profiles during the period from 1 to 24 Jan (5) are shown in purple, and from 25 Jan to 20 Feb (4) in blue. The full paths of both sg014 and sg015 are shown in dashed in (d) with the subset of profiles coming from the solid black transect (sg015) and solid gray transect (sg014). The Argo float profiles are given by the colored circles.

anomaly is calculated relative to the mean potential density of $1032.33 \mathrm{~kg} \mathrm{~m}^{-3}$ for the convecting region measured by gliders. The standard deviation of density anomaly for a profile is an indicator of how well mixed the profile is (a small standard deviation is vertically well mixed, while a larger standard deviation is associated with a more stratified profile, owing to the density change between the light surface waters and dense deeper waters). For a more quantitative measure, the stratification can be estimated as the amount of buoyancy that must be removed (e.g., through surface fluxes during convection) in order for the water column to mix down to a depth $h$ with subsequent uniform density. This quantity is called convection resistance and is defined as

$$
\mathrm{CR}(h)=\int_{-h}^{0} \sigma_{1}(S, \theta, z) d z-h \sigma_{1}(S, \theta, h)
$$

with units of kilograms per meter squared, which scales with buoyancy (Bailey et al. 2005). (Multiplying by gravitational acceleration gives units of kilograms per meter per second squared or energy per unit volume.) In this formulation, a stratified water column will have a negative CR while a well-mixed water column has a CR of zero. Unstable stratification would have a positive CR, with dense water over light. Unstable stratification could be present briefly during deep convection, but would rapidly overturn, mixing down to the convection depth.
From the hydrographic profiles and also as later observed in the convection resistance profiles, we find wellmixed profiles to 700 or more meters deep; in some cases to the full depth of the $1000 \mathrm{~m}$ observable by Seaglider. However, other profiles, both from Seaglider and Argo show property and density variations at 800 or $900 \mathrm{~m}$. Because our discussion concerns active deep convection, we choose a fixed limit of $700 \mathrm{~m}$ for the lower limit of integration in later calculations of stratification. Below this depth, several profiles become stratified. In calculating convection resistance, the contribution by this deep stratification would be indistinguishable from profiles with a stratified surface layer and weakly stratified deeper layer.

\section{Convective hydrography}

During deep convection, surface heat fluxes exceeded $1000 \mathrm{~W} \mathrm{~m}^{-2}$ and winds exceeded $25 \mathrm{~m} \mathrm{~s}^{-1}$ (not shown), driving buoyancy-driven overturning and turbulent mixing. Near the peak of convection as observed by the gliders, Seaglider profiles from 25 January to 13 February showed $\sigma_{1}$ ranges from the surface to $1000-\mathrm{m}$ of less than $0.01 \mathrm{~kg} \mathrm{~m}^{-3}$ (Fig. 2c). Within this patch of vertically well-mixed profiles however, mixed layer-averaged temperatures and salinities ranged from $3.34^{\circ}$ to $3.6^{\circ} \mathrm{C}$ and from 34.83 to 34.86 , respectively (Figs. 2a,b). While temperature and salinity were partially compensatedwhere density variations due to temperature cancelled 


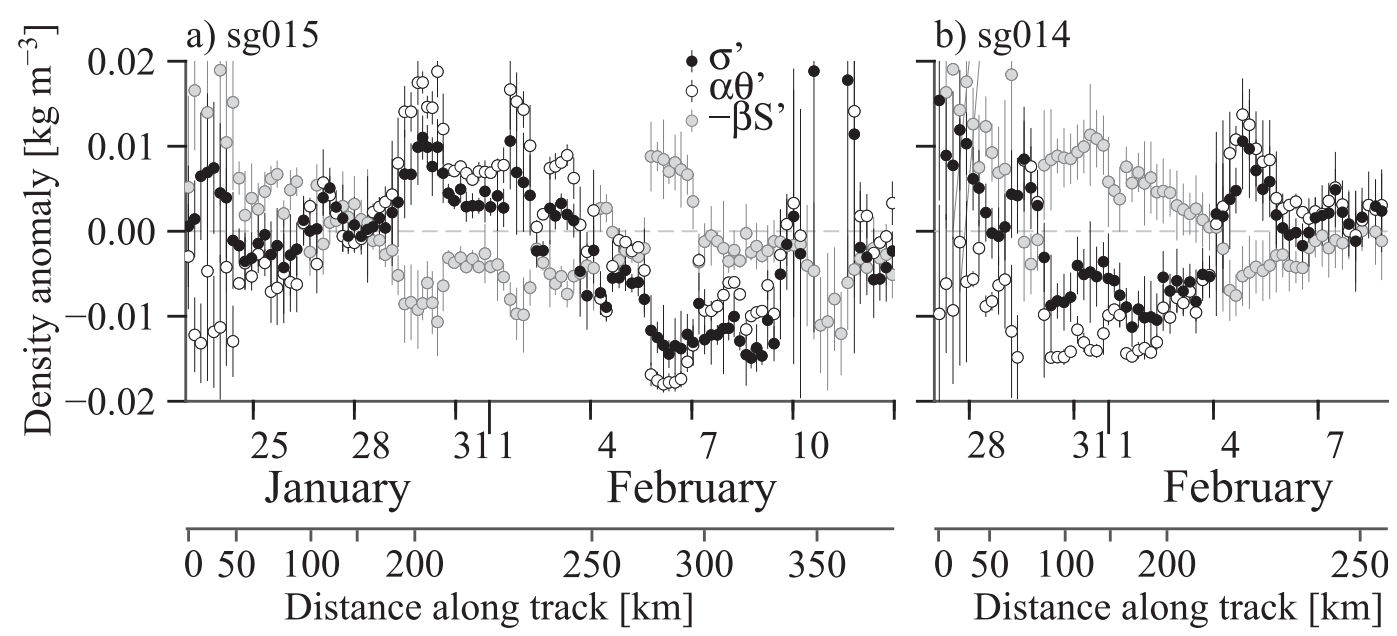

FIG. 3. Mean mixed-layer density anomaly for each profile (black) with the std devs ( \pm ) for the profile, calculated between the surface and $700 \mathrm{~m}$, marked as a vertical bar for (a) $\operatorname{sg} 015$ and (b) $\operatorname{sg} 014$. Anomalies are calculated relative to $\theta=3.5^{\circ} \mathrm{C}, S=34.85$, and $\sigma_{1}=32.33 \mathrm{~kg} \mathrm{~m}^{-3}$. Positive anomalies are less dense. Small std devs indicate a high degree of vertical homogeneity. The temperature contribution to density $\alpha \theta^{\prime}$ is given by the black open circle, and the salinity contribution $-\beta S^{\prime}$ by the gray filled circle. When the signs of the temperature and salinity contributions are opposites, they are density compensating. When the sign of the temperature or salinity contribution is the same as the density anomaly, they are controlling the density.

variations due to salinity (warmer but saltier, or colder but fresher) - the observed $\sigma_{1}$ in the convection region ranged from 32.323 to $32.343 \mathrm{~kg} \mathrm{~m}^{-3}$. These ranges represent the maximal range of salinity, potential temperature, and potential density for glider mixed layer properties, from profiles where mixed layer depths were deeper than $700 \mathrm{~m}$.

While the profiles show a large range in properties and densities, they do not indicate whether the variations are part of a background gradient in space or time, or fluctuations in values as the glider progresses through the convecting patch. To evaluate the spatial-temporal evolution of density, salinity, and temperature, we calculate the mean and standard deviation of density for each profile, plotted against time and space (Fig. 3).

While the standard deviation is low for an individual profile, indicating well-mixed profiles, the changes in mean density between profiles is substantial (on the order of $0.01 \mathrm{~kg} \mathrm{~m}^{-3}$ ). We note that $\mathrm{sg} 015$ shows a reduction in density between 25 and 29 January and a subsequent increase from 2 to 9 February. On the other hand, sg014 shows an increase in density from 28 January to 1 February and a reduction from 1 to 5 February. The profile-averaged density anomaly has a local maximum on 30 January and local minimum on 8 February with a difference of $0.026 \mathrm{~kg} \mathrm{~m}^{-3}$. From 28 to 29 January, over 3 dive cycles ( 6 profiles $\approx 15.1 \mathrm{~km}$ over ground), density changes by $0.010 \mathrm{~kg} \mathrm{~m}^{-3}$. Similar changes of $0.010 \mathrm{~kg} \mathrm{~m}^{-3}$ were observed from 3 to 4 February over 5 profiles (13.9 km over ground).
Overall, there is no monotonic tendency in the glider data toward denser water, as might be expected if the gliders were observing purely temporal evolution. Considering temperature separately, we see a change from colder to warmer waters in sg015 data as observations measure lighter water, followed by a change toward colder waters. Because the heat flux over these periods was net cooling of the ocean (Fig. 4), in a onedimensional, temporal evolution of the profile, we would expect to see only cooling of water temperatures. Because the cooling is due to cold, dry air off of Siberia and the Canadian Archipelago, we might further expect concurrent evaporation. Instead, we see changes of observed temperatures from warmer to colder with salinity changes from saltier to fresher. Together, these show that the variations in properties through the actively convecting patch must be at least partially due to horizontal variations in properties rather than purely temporal evolution.

Nine profiles from Argo floats show well-mixed layers deeper than $700 \mathrm{~m}$ (Fig. 2). The profile locations tended to be in the south and southeast portion of the region of interest, whereas Seaglider data were more northerly. In addition, the Argo float data were from late January through mid-March, potentially seeing more fully developed deep convection. Indeed, in comparing the Argo profiles to Seaglider data, the Argo data span about half the density (temperature and salinity) range as that seen by Seagliders. They also tend toward denser, colder, and fresher than the bulk of the Seaglider data. It 

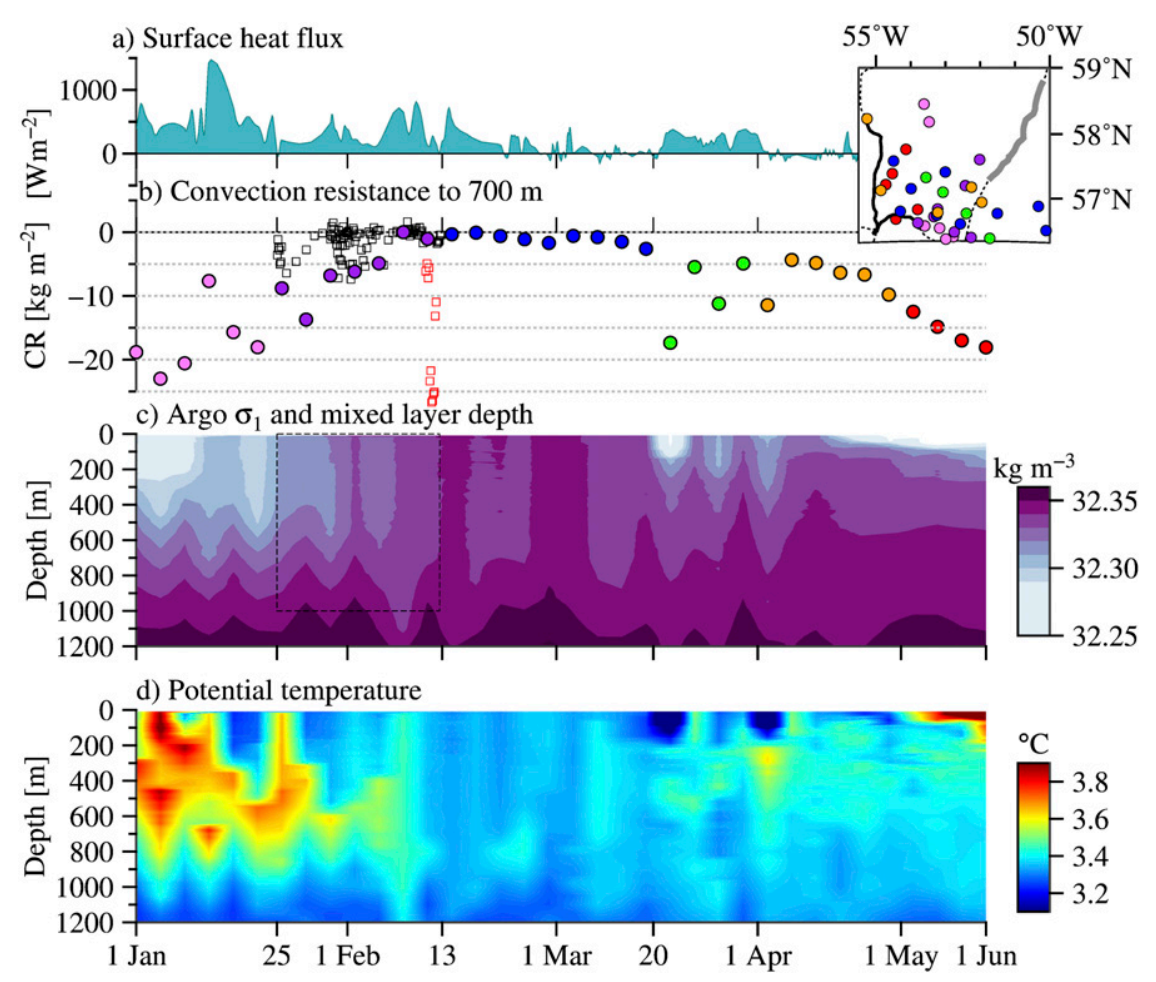

FIG. 4. Evolution of stratification. (a) Heat flux derived from NCEP-NCAR Reanalysis II in the region. (b) Convection resistance from sg015 (squares) and Argo float (circles) down to $700 \mathrm{~m}$. Near-zero values indicate well-mixed profiles, while negative values indicate stratified regions. The red squares are from a stratified eddy, surrounded by deep convection, and were excluded from Fig. 5 in order for the conclusions to be more conservative. Colors for Argo profiles indicate the time period. (c) Argo $\sigma_{1}$, shaded. The dashed black line shows the period and depth range of the glider observations. (d) Argo $\theta$, shaded. The inset map shows the location of Argo profiles. Note that the time axis in all cases has been stretched so that each profile is given equal weight in the figure, even though they may be unevenly spaced in time.

is interesting to note, however, that while the Argo float profiles included data past the observational period of the gliders, there is still no bulk change from the Argo profiles in 25 January-13 February toward colder and denser profiles in the 14 February-15 March period.

While both these pieces of evidence may indicate striking spatial variability in water mass properties and density during deep convection, we do not expect the observed variability to be entirely due to spatial variations. Over the 2.5 weeks of glider observations, we expect convective processes to vary on short ( 1 day) time scales (Frajka-Williams et al. 2011), as vertical velocities respond to changes in heat flux within 1 day. Convection is a process of surface cooling, sinking of newly densified waters, and horizontal slumping across the subsequent lateral gradients in density on short time scales. Even so, based on these observations showing nonmonotonic changes in density across short spatial scales and in the absence of a more complete dataset, we will make the assumption that the glider data are a representative snapshot of active convection and will treat the variations in properties as only spatial. The limited extent of glider data suggests that the observed variations form a lower bound to density variations that may have been observed during this time period (from late January to mid-February) given a more complete coverage of the convective patch.

\section{Evolution of stratification}

The evolution of convection can be seen in the Argo profiles of density, with an increase in surface density to a maximum in mid-February and mid-March (Fig. 4c). In late March, one of the Argo floats observed properties within an eddy with a cold, fresh surface layer, though the other float in the region also showed restratification. (In the depth-time swath in Fig. 4c, these two floats are interspersed in time, suggesting temporal variability, but because they are in two different parts of the region, the variations are due to one float being 
within an eddy and the other without.) Stratification continues to increase as thermal warming shows a net heating of the oceans (Fig. 4a).

Post deep convection, an Argo hydrographic profile from 23 March (not in an eddy) showed a density difference of $0.015 \mathrm{~kg} \mathrm{~m}^{-3}$ from the surface to $700 \mathrm{~m}$. This is immediately after the surface has restratified. This vertical density difference is of similar magnitude to the horizontal variations in density observed by $\mathrm{sg} 015$ (e.g., from 30 January to 8 February, 9 days and $100 \mathrm{~km}$, sg015 sees a horizontal range of $0.026 \mathrm{~kg} \mathrm{~m}^{-3}$ ). Vertical density variations on the same order of magnitude as horizontal are not common and already hint at the potential contained by the horizontal variations in the glider data. However, using density difference as a metric does not fully capture the stratification in the water column. For the 23 March profile, some of this density difference can be accounted for by a buoyant layer at the surface. The convection resistance from the surface to $700 \mathrm{~m}$ for 23 March is $\operatorname{CR}(700)=-5.5 \mathrm{~kg} \mathrm{~m}^{-2}$, which is outside the mean and standard deviation of the $\mathrm{CR}(700)$ from glider profiles during deep convection of $-1.4 \pm$ $2.1 \mathrm{~kg} \mathrm{~m}^{-2}$ (excluding the 12 profiles in the stratified eddy). The overall range in CR(700) from the Argo floats is from 0 to -10 between 6 February and 27 April.

In April, there is a change in sign of surface heat flux from positive (cooling of the ocean) to negative (warming of the ocean, Fig. 4a). This is followed by an increase in the temperature contribution to stratification (not shown). The magnitude of convection resistance increases to $<-5 \mathrm{~kg} \mathrm{~m}^{-2}$, more negative than the convection resistance estimates from deeply convecting Seaglider profiles. From Argo hydrographic profiles, the profile of CR referenced to $700 \mathrm{~m}$ indicates low stratification, near-zero CR on 6 February $\left(0.01 \mathrm{~kg} \mathrm{~m}^{-2}\right)$ while on 4 May, in restratified water, the CR becomes more negative $\left(-12.5 \mathrm{~kg} \mathrm{~m}^{-2}\right)$.

\section{Buoyancy content during convection versus restratified waters}

In the previous section, we compared the $\mathrm{CR}(700)$ values from Argo to those from Seaglider, where in both cases, the CR was referenced to the density at $700 \mathrm{~m}$ for that profile. We now average together profiles of $\operatorname{CR}(z)$ referenced to each depth, to create a convective-patch average of CR (see Fig. 5, black with shading to indicate the standard deviation at each depth). The result indicates low stratification, with an average CR(700) near zero $\left(-1.4 \mathrm{~kg} \mathrm{~m}^{-2}\right)$. The profiles of CR confirm what was visible in the property profiles (Figs. 2a-c): that individual profiles are vertically well mixed.

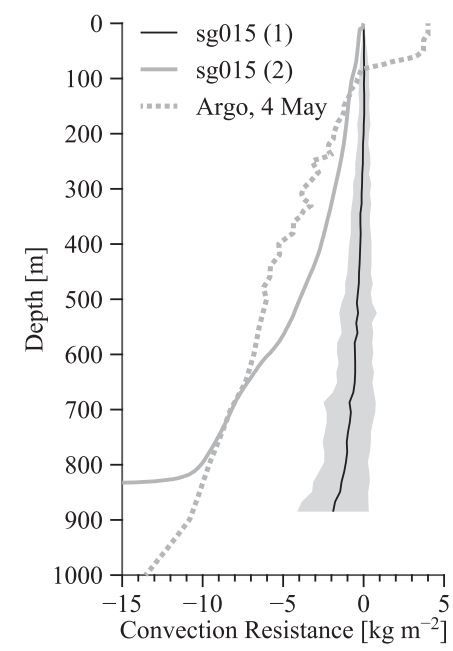

FIG. 5. CR profiles for sg015 and Argo float. The thin black line (1) is the average ( \pm std dev, shading) of convection resistance profiles from sg015 calculated within the convection region above the mixed layer depth. The solid gray line (2) is the convection resistance calculated from the resorted density profile of all sg015 densities within the mixed layers deeper than $400 \mathrm{~m}$. The Argo profile plotted is from 4 May (gray dashed), offset by $4.28 \mathrm{~kg} \mathrm{~m}^{-2}$ to align at $700 \mathrm{~m}$ with the glider profile. The Argo float shows a similar degree of stratification between 100 and $800 \mathrm{~m}$ deep as the sorted glider profile.

Now, to quantify the overall buoyancy available in the convecting region, allowing for spatial variations in density, we will reference CR to the same density for each profile. We are assuming that the variations in density observed by Seaglider are due purely to horizontal variations rather than temporal variations (section 3). We use reference values of $S_{0}=34.84, \theta_{0}=$ $3.37^{\circ} \mathrm{C}$, and $h=700 \mathrm{dbar}$, where $S_{0}$ and $\theta_{0}$ were mean values of salinity and temperature in the top $700 \mathrm{~m}$ during deep convection from 27 January to 26 February in Argo data. The observed convecting state was horizontally stratified but vertically well mixed, while the final state is now presumed to be relatively horizontally homogenous and vertically stratified (Fig. 4c). To estimate the buoyancy available in the convecting region sampled by Seaglider, we adiabatically sort the density measurements into the state of lowest potential energy, with the densest measurements at the bottom $(1000 \mathrm{~m})$ of the measured volume along the Seaglider transect and the lightest at the surface. Given that the glider data were gridded onto a regular 2-dbar grid, the result is a set of the same number of profiles, now horizontally homogenous and vertically stratified set of profiles. Averaging across this set, we then have a single profile representative of this sorted state. This offers an estimate of the bulk stratification of the convecting volume. From this single sorted density profile, we can 
then calculate a bulk convection resistance to represent the buoyancy available in the original profiles from the convecting region. For the sorted profile, the $\mathrm{CR}$ at $700 \mathrm{~m}$ is $-8.3 \mathrm{~kg} \mathrm{~m}^{-2}$. Thus, CR from the sorted Seaglider data matches (or is even more stratified than) the CR from 20 April from Argo $\left[\mathrm{CR}(700)=-6.7 \mathrm{~kg} \mathrm{~m}^{-2}\right.$, Fig. 4b]. This indicates that from Seaglider observations during deep convection, there appears to be sufficient buoyancy available to restratify the region to observed April levels of stratification.

Looking in more detail at the Argo data from 20 April, we see that this enhanced CR can be at least partially attributed to a surface fresh layer (Figs. 4c,d). Comparing just the subsurface stratification, we find that the profile of CR from 4 May is quite similar to that of the sorted glider data (Fig. 5). In particular, by shifting the $\mathrm{CR}(z)$ from 4 May to match that of the sorted glider profile at $700 \mathrm{~m}$, the profile of CR between 100 and $700 \mathrm{~m}$ closely resembles that of the sorted glider profile. The offset difference between 100 and $600 \mathrm{~m}$ can be explained by where the $\mathrm{CR}$ profiles had stronger slopes (indicating stronger stratification). In the Argo profile between 100 and $400 \mathrm{~m}$, there was slightly stronger stratification than the sorted glider profile, while the sorted glider profile had increased stratification between 500 and $650 \mathrm{~m}$. The Argo profile shows quite strong stratification at $80-100 \mathrm{~m}$ where the transition between the surface buoyant layer and more weakly stratified subsurface layer occurs.

Our method of comparing a sorted glider profile to the Argo profile assumes that the restratification of the glider data is purely adiabatic. By comparing the sorted profile with Argo data, we are further assuming that the two datasets are representative of the same volume of water. If this were the case, then the volume of water in a particular $\theta-S$ class would not change from the convecting period to the restratified profile on 20 April. To check this, the volumetric $\theta-S$ diagram was calculated from the Seaglider data (25 January-13 February) in bins of 0.002 salinity and $0.01^{\circ} \mathrm{C}$ (see Fig. 6). The Argo profiles from 13 April to 4 May suggest that while the bulk of the water did not change in salinity, from the Seaglider observations to the Argo profile, the temperature continued to cool. This is indicated by the absence of Argo temperatures above about $3.5^{\circ} \mathrm{C}$. In addition, in the Argo profiles, there is a $50-100 \mathrm{~m}$ surface layer that is very fresh $(S<34.8)$ and cold $\left(\theta<3.4^{\circ} \mathrm{C}\right.$, except 4 May, where $\theta \approx 3.54^{\circ} \mathrm{C}$ ).

The temperature difference between the Argo profile and the largest volumes of convecting water in the Seaglider data may be attributed to the fact that the Seaglider left the region before the deepest mixed layers were observed (Fig. 4c). Indeed, the Argo floats show

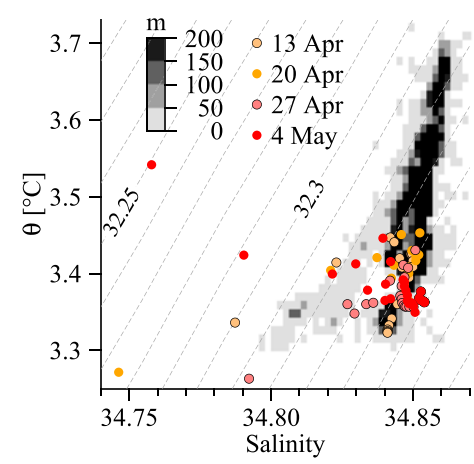

FIG. 6. Volumetric $\theta-S$ diagram from $\operatorname{sg} 015$ data (25 Jan-13 Feb) in gray shading, where the numbers indicate meters of thickness of water within a particular 0.002 salinity and $0.01^{\circ} \mathrm{C}$ bin. Only profiles with mixed layer depths greater than $400 \mathrm{~m}$ were used (excluding the eddy from 10 to $12 \mathrm{Feb} 2005$ ). The contours are $\sigma_{1}$ at $0.01 \mathrm{~kg} \mathrm{~m}^{-3}$ intervals. The Argo float data are given by colored circles where each circle represents $50 \mathrm{~m}$ thickness of water with the given average properties. The small scattering of circles at salinities less than 34.8 indicate that some freshwater has been imported to the region. It also suggests that temperatures continued to cool past when the glider was in the convecting region.

vertically homogenous profiles through mid-March, while the gliders moved out of the convection region in mid-February. While from mid-February to mid-March, the Argo profiles do not show a continued trend toward colder or denser convecting water (Fig. 5d), the glider observations from late January to mid-February were warmer, on average, than in mid-February. This suggests that while gliders clearly observed active, deep convection with vertically well-mixed profiles from late January (near-zero CR, Fig. 4b), the properties of the convecting water did gradually cool until mid-February, when they appear to stabilize. This potential continued cooling may have been accompanied by additional horizontal homogenization (not observable with the present dataset). If this was the case, then the estimates of horizontal density variability from the Seaglider data may be an overestimate of the buoyancy available immediately prior to restratification.

The fresh surface layer visible in the $\theta-S$ diagram of the Argo profile indicates that the fresh layer must have been imported to the region, as water this low in salinity is not present in the glider observations. Even so, the convection resistance in the 4 May Argo profile is dominated by stratification below $100 \mathrm{~m}$, which matches the convection resistance in the sorted Seaglider profile (Fig. 5).

\section{Discussion}

Seaglider observations in January-February 2005 from a deep convecting patch within the Labrador Sea 
show vertically well-mixed profiles of temperature, salinity, and density. However, over the $350-\mathrm{km}$-wide patch observed by sg015 and $250-\mathrm{km}$-wide patch observed by sg014, glider data exhibited substantial density variations between the vertically well-mixed profiles. In the case of $\mathrm{sg} 015$, variations were as much as $0.026 \mathrm{~kg} \mathrm{~m}^{-3}$ over just 9 days, or a density difference of $0.01 \mathrm{~kg} \mathrm{~m}^{-3}$ across $15 \mathrm{~km}$ horizontally. These density differences are similar to those used to determine how well a profile is mixed, where the threshold of $0.01 \mathrm{~kg} \mathrm{~m}^{-3}$ in density is a common choice in the vertical for determining the mixed layer depth in the Labrador Sea. While the convecting region was observed over a span of 2.5 weeks (late January-mid-February), and from Argo float profiles we find that convection proceeded beyond the time that the gliders were there (through mid-March), the observed variations in temperature and density do not indicate a monotonic change toward denser and colder waters, as might be expected of a purely temporal change due to the net cooling by the atmosphere.

Based on these observations, we treat the observations from Seaglider as purely spatially varying, while in reality, they will be a mix of spatial and temporal variations. Under this assumption, by comparing the buoyancy available in the convecting volume from Seagliders (from late January to mid-February), with an estimate of buoyancy in restratified profiles from Argo in the same region, we find that the buoyancy available due to lateral variations in density is sufficient to restratify the region to the observed stratification in April. If we further exclude the fresh surface layer from Argo profiles, then the convecting profiles from Seaglider show stratification similar to that from Argo data in May.

These finescale lateral heterogeneities in density may contribute to the difficulty that climate models have in representing convection and restratification. The Seaglider observations show nonnegligible density differences on the scale of tens of kilometers, while most climate models tend to be run at $100-\mathrm{km}$ scales. In addition, the density overturns that cause convection invalidate the hydrostatic assumptions of models (that profiles are stably stratified). As a consequence, convection is often too deep or too persistent in numerical models. Numerical studies have investigated restratification processes, involving lateral fluxes of buoyant waters from outside the convection region (Katsman et al. 2004; Jones and Marshall 1997; Chanut et al. 2008; Gelderloos et al. 2011), but typically considering longer, annual time scales.

The immediate cessation of convection is likely to be enhanced or enabled by the density variations within the convecting patch, without invoking lateral fluxes from further away. Recent observations and simulations in the nearby Irminger Sea found that mixed layer eddies were responsible for the short time scale of restratification, prior to thermal warming (Mahadevan et al. 2012). These observed density variations may reduce the time to restratification, ending convection sooner and changing the estimates of deep water formation volume and properties.

Acknowledgments. E. F. was supported by an NSF graduate research fellowship for a part of this work. Seaglider missions in the Labrador Sea were funded by the U.S. National Oceanic and Atmospheric Administration Arctic Research Office. Many thanks to Jonathan Lilly, Erik van Sebille, Eric Kunze, and Eric D'Asaro for helpful discussions.

\section{REFERENCES}

Bailey, D. A., P. B. Rhines, and S. Hakkinen, 2005: Formation and pathways of North Atlantic Deep Water in a coupled iceocean model of the Arctic-North Atlantic Oceans. J. Climate, 25, 497-516.

Boccaletti, G., R. Ferrari, and B. Fox-Kemper, 2007: Mixed layer instabilities and restratification. J. Phys. Oceanogr., 37, 2228 2250

Chanut, J., B. Barnier, W. Large, L. Debreu, T. Penduff, J. M. Molines, and P. Mathiot, 2008: Mesoscale eddies in the Labrador Sea and their contribution to convection and restratification. J. Phys. Oceanogr., 38, 1617-1643.

Cole, S. T., D. L. Rudnick, and J. A. Colosi, 2010: Seasonal evolution of upper-ocean horizontal structure and the remnant mixed layer. J. Geophys. Res., 115, C04012, doi:10.1029/ 2009JC005654.

Frajka-Williams, E., C. C. Eriksen, P. B. Rhines, and R. R. Harcourt, 2011: Determining vertical velocities from Seaglider. J. Atmos. Oceanic Technol., 28, 1641-1656.

Gelderloos, R., C. A. Katsman, and S. S. Drijfhout, 2011: Assessing the roles of three eddy types in restratifying the Labrador Sea after deep convection. J. Phys. Oceanogr., 41, 2102-2119.

Jones, H., and J. Marshall, 1997: Restratification after deep convection. J. Phys. Oceanogr., 27, 2276-2287.

Katsman, C. A., M. A. Spall, and R. S. Pickart, 2004: Boundary current eddies and their role in the restratification of the Labrador Sea. J. Phys. Oceanogr., 34, 1967-1983.

Lavender, K. L., W. B. Owens, and R. E. Davis, 2005: The middepth circulation of the subpolar North Atlantic Ocean as measured by subsurface floats. J. Phys. Oceanogr., 52, 767785 .

Lazier, J., R. Hendry, A. Clarke, I. Yashayaev, and P. Rhines, 2002: Convection and restratification in the Labrador Sea, 19902000. Deep-Sea Res. I, 49, 1819-1835.

Legg, S., and J. C. McWilliams, 2000: Temperature and salinity variability in heterogeneous oceanic convection. J. Phys. Oceanogr., 30, 1188-1206.

Lilly, J. M., P. B. Rhines, M. Visbeck, R. Davis, J. R. N. Lazier, F. Schott, and D. Farmer, 1999: Observing deep convection in the Labrador Sea during winter 1994/95. J. Phys. Oceanogr., 29, 2065-2098. 
Mahadevan, A., E. D'Asaro, C. Lee, and M. J. Perry, 2012: Eddydriven stratification initiates North Atlantic spring phytoplankton blooms. Nature, 337, 54-58.

Marshall, J., and F. Schott, 1999: Open-ocean convection: Observations, theory and models. Rev. Geophys., 37, 1-64.

Renfrew, I. A., G. W. K. Moore, P. S. Guest, and K. Bumke, 2002: Comparison of surface layer and surface turbulent flux observations over the Labrador Sea with ECMWF analyses and NCEP reanalyses. J. Phys. Oceanogr., 32, 383-400.

Schmidt, S., and U. Send, 2007: Origin and composition of seasonal Labrador Sea freshwater. J. Phys. Oceanogr., 37, 1445-1454.
Steffen, E. L., and E. A. D'Asaro, 2002: Deep convection in the Labrador Sea as observed by Lagrangian floats. J. Phys. Oceanogr., 32, 475-492.

Straneo, F., 2006: Heat and freshwater transport through the central Labrador Sea. J. Phys. Oceanogr., 36, 606-628.

Timmermans, M.-L., S. Cole, and J. Toole, 2012: Horizontal density structure and restratification of the Arctic Ocean surface layer. J. Phys. Oceanogr., 42, 659-668.

Visbeck, M., J. Marshall, and H. Jones, 1996: Dynamics of isolated convective regions in the ocean. J. Phys. Oceanogr., 26, 17211734 . 